\title{
REPORT \\ A Visit to the Walter Reed Institute, Washington
}

Maj AMJ Croft

MA, MSc, MBBS, MIL, DMCC, MFPHM, RAMC

MOD HQ DSCA, St Gile's Court, 1-13 St Gile's High

Street, London WC2H $8 L D$.

The Walter Reed Army Institute of Research (WRAIR) in Washington is about the size of St Thomas' Hospital. Directly behind it is a brand new secondary care facility, the Walter Reed Military Hospital, also about the size of St Thomas'. When I looked in at the vast entrance lobby of the hospital, I was struck by a fifty-foot banner which read: WALTER REED MILITARY HOSPITAL - NO 1 FOR PATIENT SATISFACTION IN THE USA. What was the evidence for this remarkable claim? I never found out, as the main purpose of my visit lay next door.

Each year the US Army spends $\$ 4.2$ million on malaria research, most of it centred on WRAIR. Malaria is the world's worst public health problem, but the rest of the world put together, including WHO and all pharmaceutical companies, only spends about $\$ 4.8$ million per year on primary research into malaria. The disproportionate research burden borne by WRAIR reflects on the determination of the US Army to conquer a disease which remains a formidable military threat.

Every Spring WRAIR hosts an "Interagency Group Meeting", drawn from malariologists around the world, to discuss current research issues in malaria. I was fortunate enough to be invited to the Spring 1998 conference, and to be granted funding from the Drummond Foundation so as to be able to attend.

Three presentations were of special interest.

LTC Steve Craig, US Army, described the resurgence of malaria in Korea, in the Demilitarised Zone (DMZ) north of the Imjin River. This has led to a malaria epidemic in the civilian population of South Korea, and to dozens of cases of Plasmodium vivax illness in US troops stationed in or passing through the DMZ. As a result, the US Army

is planning for the first time in thirty years to insist chemoprophylaxis for its troops in Korea.

COL Wilbur Milhous, Chief of the Division Experimental Therapeutics at WRAIR, spoke about nea drugs under development. These are needed to combâa parasites which have become "multidrug resistant", arf also to replace the WRAIR-produced drug mefloquine ( $\overrightarrow{\ddot{\theta}}$ Lariam) which has caused many problems in travelleos worldwide on account of its tendency to indu neuropsychiatric illness. The two most promisin chemoprophylactic drugs in development, both currently at the stage of Phase 3 randomised controlled trials, at WR 238605 (or Etaquine), and atovaquone-proguanil (ه্ Malarone).

Dr Monica Paresi, of the Centers for Disease Contr $\Leftrightarrow$ (CDC) Atlanta, demonstrated a new use for telemedicine in the diagnosis and management of parasitic disea Registered users of a newly-developed CDC websited (G. www.ncid.cdc.gov/dpdx) can now send scanned electr $\vec{g}$ R images of Plasmodia and other human parasites to angare call CDC pathologist from anywhere in the world, बifts receive a provisional diagnosis and treatment ado within 24 hours. Registration with CDC, and subseq use of the service, are both free.

I found my visit to WRAIR hugely informative, very relevant to some of the perennial health concerns the British Army. I am most grateful to the Trustees of the Drummond Foundation for having made my trip possible and to Dr Paul Garner of the Cochrane Infectious Diseases Group, Liverpool School of Tropical Medicine, fof encouraging me to develop a special interest in this field of medical research. 